\title{
SOLIDARITAS SOSIAL DALAM MARGINALISASI MASYARAKAT MISKIN (Studi di Dusun Kentheng Kota Surakarta)
}

\author{
Khalis Asyifani, Muhammad Alif Alauddin, Herlina, Khexe Purnamasari \\ Program Studi Sosiologi,Fakultas IImu Sosial dan Politik, \\ Universitas Sebelas Maret \\ E-mail: khalisyifa@student.uns.ac.id
}

\begin{abstract}
Abstrak
Kemiskinan adalah permasalahan sosial yang erat kaitannya dengan masyarakat marginal. Ukuran kemiskinan umumnya menggunakan pendekatan ekonomi, sehingga tingkat pemenuhan kebutuhan pokok menjadi perhatian yang dianggap paling penting. Akan tetapi ditinjau dari tingkat pemenuhan hidup di kota, dapat dipahami bahwa kemiskinan tidak berkata demikian, namun kebudayaan yang muncul sebagai warisan dari generasi tua yang terbelakang. Penelitian ini bertujuan untuk menjelaskan hubungan antara kemiskinan pada masyarakat pinggiran dengan solidaritas sosial yang terjadi di dalamnya. Metode penelitian yang digunakan yaitu metode penelitian kualitatif dengan pendekatan studi kasus. Pemilihan informan menggunakan teknik purposive sampling. Pengumpulan data dilakukan melalui observasi, studi literatur, studi dokumentasi, Peer-Group Discussion bersama mahasiswa Sosiologi FISIP UNS di bawah supervisi sosiolog pedesaan, serta wawancara mendalam. Hasil penelitian menunjukan bahwa (1) latar belakang kemiskinan yang sama menyebabkan gaya hidup gotong royong. (2) Solidaritas ini membuat masyarakat tetap dapat memenuhi kebutuhan hidupnya. (3) Solidaritas diantara mereka membuat mereka bisa bertahan hidup ditengah kemiskinan. Solidaritas sosial menjadi faktor keberlangsungan hidup mereka.
\end{abstract}

Kata Kunci: Kemiskinan, Masyarakat Marginal, Permasalahan Perkotaan

\section{Abstract}

Poverty is a social problem closely related to marginalized communities. The measure of poverty is generally obtained through an economic approach, so that the level of fulfillment of basic needs becomes the most important standout. However, based on the level of fulfilment of life in the city, it is understandable that poverty is not the case, but the culture that emerges as the legacy of the underdeveloped older generation. This study aims to explain the relationship between poverty in marginal communities and the social solidarity that occurs within it. The research method used is a qualitative with a case study approach. The informant is purposively selected. Data collection was conducted through observations, literature studies, documentation studies, Peer-Group Discussions with sociology students of FISIP UNS under the supervision of rural sociologists, as well as in-depth interviews. The results of the study show that (1) the common poverty background causes a lifestyle of mutual cooperation. (2) This solidarity keeps the community able to meet their needs. (3) Solidarity between them enables them to survive amidst poverty. Social solidarity is a factor in their survival.

Keyword: Poverty, Marginal Society, Urban Problems 


\section{Pendahuluan}

Kemiskinan merupakan salah satu masalah utama yang dihadapi negara berkembang (Klasen, 2009). Kondisi tersebut biasa terjadi dalam sebuah negara yang padat penduduk seperti Indonesia. Hal ini menjadi masalah serius yang wajib diperhatikan oleh pemerintah agar dapat segera diatasi. Kemiskinan dapat terjadi di mana saja baik di pedesaan maupun perkotaan. Di wilayah perkotaan, bentuk kemiskinan digambarkan dengan integrasi masyarakat dalam sebuah kawasan yang terpinggirkan (Wratten, 1995).

Padatnya penduduk di wilayah perkotaan bisa terjadi karena beberapa faktor. Orang-orang yang memutuskan bermigrasi ke kota biasanya didukung oleh terbatasnya lapangan pekerjaan di desa, sulitnya akses teknologi, hingga keinginan untuk melanjutkan pendidikan yang lebih bergengsi di kota. Meski begitu, migrasi ke kota tidak selalu menyelesaikan permasalahan yang diperoleh tiap individu di desa. Orangorang yang bermigrasi tanpa memiliki kemampuan bersaing yang baik hanya akan menimbulkan masalah baru di kota, salah satunya adalah kemiskinan.
Masyarakat desa yang berpindah ke kota memiliki harapan untuk mendapat pekerjaan yang layak. Kota memang menawarkan variasi pekerjaan, namun jika orang-orang datang tanpa kemampuan lebih, paling cepat mereka hanya akan menjadi pekerja serabutan. Menurut Badan Pusat Statistik, pada tahun 2018 sejumlah 9,66\% penduduk di Indonesia merupakan masyarakat miskin. Penduduk miskin yang terintegrasi dalam suatu kawasan kemudian disebut sebagai masyarakat marginal atau masyarakat terpinggirkan.

Namun meskipun mereka tidak mampu memperoleh penghasilan yang cukup untuk kebutuhan sehari-hari, kelompok masyarakat ini memiliki solidaritas sosial yang kuat. Kota-kota besar di Indonesia seperti di Jakarta, Semarang, Yogyakarta, Surabaya, hingga Surakarta mengalami permasalahan tersebut. Di Surakarta, bentuk kemiskinan kota terintegrasi pada sebuah kawasan kumuh di Dusun Kentheng Desa Semanggi Pasar Kliwon.

Menurut Jellinek masyarakat miskin pedesaan yang terdorong dari daerahnya hidup berkelompok dan membentuk kampung 
kumuh di kota. Mereka hidup berdampingan dan saling tolong menolong sesama perantau. Hal tersebut menjadi kekuatan sosial diantara masyarakat miskin kota. Penelitian ini mengulas tentang bentuk marginalisasi masyarakat miskin kota di Dusun Kentheng Kota Surakarta dan solidaritas sosial yang terbentuk antar warga setempat.

\begin{tabular}{ccc}
\hline Nama & Pekerjaan & $\begin{array}{c}\text { Lama } \\
\text { Tinggal }\end{array}$ \\
\hline Eko & $\begin{array}{c}\text { Kuli } \\
\text { Bangunan }\end{array}$ & 26 Tahun \\
\hline Ulfah & $\begin{array}{c}\text { Berjualan di } \\
\text { warung }\end{array}$ & 2 Tahun \\
\hline Hanifah & $\begin{array}{c}\text { Guru } \\
\text { Mengaji }\end{array}$ & 7 Tahun \\
\hline \multicolumn{3}{c}{ Sumber: Data Primer }
\end{tabular}

\section{Hasil dan Pembahasan}

\section{Metode}

Penelitian ini merupakan penelitian kualitatif studi kasus dengan pengambilan sampel menggunakan teknik purposive sampling. Teknik pengumpulan data dilakukan melalui observasi, studi literatur, studi dokumentasi, Peer-Group Discussion bersama mahasiswa Sosiologi FISIP UNS di bawah supervisi sosiolog pedesaan, serta wawancara mendalam terhadap 3 informan yang merupakan warga di Dusun Kentheng. Penelitian ini menjelaskan hubungan antara marginalisasi masyarakat miskin dengan solidaritas sosial di Dusun Kentheng Kelurahan Semanggi Pasar Kliwon Surakarta. Data tersebut diolah melalui reduksi kemudian dianalisis untuk memperoleh hasil dari penelitian.

Kemiskinan dapat dicirikan dengan ketidakmampuan untuk memenuhi berbagai kebutuhan pangan, perumahan dan pakaian, tingkat pendapatan rendah, pendidikan dan keahlian rendah, keterkucilan sosial karena keterbatasan kemampuan untuk berpartisipasi dalam kegiatan sosial kemasyarakatan. Singkatnya, kemiskinan dapat didefinisikan sebagai suatu standar hidup yang rendah yaitu suatu tingkat kekurangan materi pada sejumlah atau segolongan orang dibandingkan dengan standar kehidupan yang umum berlaku dalam masyarakat yang bersangkutan (Suparlan,1984).

Kondisi masyarakat yang disebut miskin dapat diketahui berdasarkan kemampuan pendapatan dalam memenuhi standar hidup (Blank et.al, 1993). Pada prinsipnya, standar hidup di 
suatu masyarakat tidak sekedar tercukupinya kebutuhan akan pangan, akan tetapi juga tercukupinya kebutuhan akan kesehatan maupun pendidikan. Tempat tinggal ataupun pemukiman yang layak merupakan salah satu dari standar hidup atau standar kesejahteraan masyarakat di suatu daerah. Berdasarkan kondisi ini, suatu masyarakat disebut miskin apabila memiliki pendapatan jauh lebih rendah dari rata-rata pendapatan sehingga tidak banyak memiliki kesempatan untuk mensejahterakan dirinya (Suryawati, 2005).

Masyarakat miskin dikategorikan dalam kelompok marginal. Masyarakat marginal adalah kelompok masyarakat yang tersisih atau disisihkan dari pembangunan sehingga tidak mendapat kesempatan untuk menikmati pembangunan (Lin et.al, 2013), atau bisa dikatakan masyarakat yang dimiskinkan oleh pembangunan.

\section{Profil Lokasi Penelitian}

Kelurahan Semanggi mempunyai luas 166.82 ha. Terletak 900 $\mathrm{m}$ dari pusat Pemerintahan Kecamatan, 3 $\mathrm{km}$ dari pusat Pemerintahan Kota dan 105 km dari pusat Pemerintahan Provinsi. Berbatasan di sebelah utara dengan Kelurahan Sangkrah Kota Surakarta, sebelah timur dengan Kelurahan Mojolaban Kabupaten Sukoharjo, sebelah selatan dengan Kelurahan Grogol Kabupaten Sukoharjo, dan di sebelah barat dengan Kelurahan Joyosuran dan Kelurahan Pasar Kliwon. Kelurahan ini berada paling Tenggara Kota Solo. Kelurahan ini merupakan bagian dari Kecamatan Pasar Kliwon. Penduduknya merupakan campuran antara masyarakat Jawa dan Arab. Semanggi bagian Timur berbatasan dengan Kabupaten Sukoharjo ditandai dengan adanya Sungai Bengawan Solo. Penduduk Kelurahan Semanggi pada tahun 2017 berjumlah 34.169 jiwa yang terdiri dari 17.112 laki-laki dan 17.057 perempuan. Berdasarkan jumlah Kartu Keluarga (KK), Kelurahan Semanggi memiliki $1.353 \mathrm{KK}$. 
Tabel 1.1

Jumlah Penduduk Menurut Tingkat Pendidikan

\begin{tabular}{ccc}
\hline No & $\begin{array}{c}\text { Tingkat } \\
\text { Pendidikan }\end{array}$ & Jumlah \\
\hline 2 & TK & 2.532 \\
\hline 3 & SD & 1.748 \\
\hline 4 & SMP & 7.226 \\
\hline 5 & SMA & 8.225 \\
\hline 6 & D3 & 809 \\
\hline 7 & S1 & 963 \\
\hline 8 & S2 & 55 \\
\hline 9 & S3 \\
\hline \multicolumn{3}{c}{ Total: 21.563 } \\
\hline \multicolumn{3}{c}{ (Sumber: Data Demografi Kelurahan }
\end{tabular}

Semanggi, 2017)

Tabel 1.2

Jenis Pekerjaan Masyarakat Kelurahan Semanggi

\begin{tabular}{ccc}
\hline No & $\begin{array}{c}\text { Jenis } \\
\text { Pekerjaan }\end{array}$ & $\begin{array}{c}\text { Presentase } \\
(\%)\end{array}$ \\
\hline 1 & PNS & 10 \\
\hline 2 & Pensiunan & 15 \\
\hline 3 & Pedagang & 35 \\
\hline 4 & Buruh & 40 \\
\hline \multicolumn{3}{c}{ Total 100\% } \\
\hline \multicolumn{3}{c}{ (Sumber: Data Demogtafi }
\end{tabular}

Kelurahan Semanggi, 2017)

Angka putus sekolah di Kelurahan Semanggi melebihi rata-rata kecamatan yaitu $7 \%$. Terdapat 572 anak putus sekolah dari keseluruhan anak usia sekolah sejumlah 5.232, angka ini tertinggi di Kota Surakarta. Kebanyakan tersebar di Semanggi selatan berbatasan dengan sungai Bengawan Solo. Minimnya fasilitas pendidikan dan pemukiman penduduk menyebabkan tingkat pendidikan masyarakat Dusun Kentheng terhitung rendah. Ditambah dengan kondisi ekonomi yang bergerak di sektor menengah ke bawah dan daya beli yang kurang menjadi beban tersendiri bagi keluarga di kawasan ini.

$$
\text { Kelurahan Semanggi juga }
$$
memiliki angka kemiskinan yang tinggi yaitu $26 \%$, lebih tinggi dari rata-rata Kecamatan yang hanya $15 \%$. Selain itu, kondisi kesehatan masyarakat juga terpengaruh akibat fenomena kemiskinan tersebut. Masalah kesehatan sering disebabkan oleh kondisi air dan udara. Buruknya drainase menyebabkan munculnya sarang nyamuk yang membawa penyakit. Penyakit yang umum menimpa masyarakat Dusun Kentheng adalah demam berdarah, diare, dan ISPA. Desa Kentheng yang dijadikan objek penelitian merupakan kawasan slum area terbesar di Surakarta.

\section{Pemaknaan Tentang Kemiskinan}
A. Persepsi Masyarakat Mengenai Kemiskinan

Masyarakat Dusun Kentheng, Semanggi memiliki persepsi yang sama 
dalam memaknai kemiskinan yaitu sebagai "Suatu kondisi kesulitan dalam mencari pekerjaan dan upah layak". Hal ini terungkap dari penuturan yang disampaikan oleh informan sebagai berikut:

" ...Di dusun ini mayoritas warga non pns (swasta), buruh, pabrik. banyak bapak bapak yang kerja serabutan...". (Wawancara dengan Eko)

"...Saya sebenernya pengangguran mas. Kerja kalau ada panggilan aja. Biasanya saya jadi tukang kayu di Jogja. Kalau ada panggilan ya Alhamdulillah kalau ndak ya disyukuri aja..." (Wawancara dengan Eko)

Salah satu faktor penyebab munculnya kawasan kumuh di perkotaan adalah banyaknya pendatang baru dari desa yang menggantungkan hidupnya pada peluang kerja di kota. Para pendatang dari desa memiliki perasaan yang sama atas perjuangan memenuhi kebutuhan hidup.

"...kebanyakan warga di sini itu pendatang. Di sini warga yang $K K$ nya asli sini sama yang pendatang banyak yang pendatang. Ini sebelah rumah saya, dari sragen, kalo ndak salah. Ini (satu lagi) sudah beberapa tahun belum pindah itu sampai sekarang. Lah saya sendiri di sini udah 5 tahun lebih...". (Wawancara dengan Hanifah)

"Saya di sini baru kemarin bulan Januari pindahan dari Malang. Di sini rumah orangtua. Baru tau kalo di sini tanahnya ndak resmi. Kemarin sempet ngajuin KK tapi ditolak, akhirnya KK dari Wonogiri tempat bapak dulu..." (Wawancara dengan Ulfa)

"...Dulu daerah sini kebun semua mas, mba. Di depan rumah saya ini dulunya tumbuhan ketela semua. Gede- gede banget. Dulu masih beberapa rumah bangunan gitu, baru beberapa rumah terus ditanami sawah, jagung sama palawija. Ya setelah itu banyak pendatang nyari kerja sampai sekarang..." (Wawancara dengan Eko)

"...Termasuk yang sawah itu, itu pendatang semua bukan warga sini. itu kan ada jalan perempatan yang mau kejalan besar..." (Wawancara dengan Eko)

Berdasarkan data dari informan, dapat dilihat bahwa faktor yang turut memengaruhi kemiskinan adalah banyaknya pendatang dari luar Kota Surakarta yang mencari pekerjaan dan menetap. Para pendatang mayoritas hanya lulusan sekolah dasar sehingga tidak memiliki kemampuan untuk bekerja di sektor formal. Kebanyakan dari mereka hanya bekerja serabutan. 
"...Waduh mas, saya terakhir sekolah itu ya SD. Biar anak saya yang sekolah tinggi-tinggi..." (Wawancara dengan Hanifah)

"...Mau nambah usaha ya ndak punya modal mas. Palingan warung ini aja dari hasil warisan orangtua. Mbok ya tamatan SD tok aku mana mudeng bisnis..." (Wawancara dengan Ulfa)

Rendahnya tingkat pendidikan dan modal merupakan penyebab kemiskinan bagi masyarakat Dusun Kentheng. Kondisi tersebut memaksa mereka melakukan pekerjaan serabutan seperti buruh, usaha warung, dan pedagang kecil karena tuntutan ekonomi agar bisa menghidupi keluarganya.

\section{Faktor Penyebab Kemiskinan}

Bila dilihat berdasarkan faktorfaktor penyebab kemiskinan yang dialami oleh masyarakat, maka dapat dibagi menjadi 4 (empat) faktor, yaitu:

A. Faktor Ekonomi

Modal dianggap sebagai
kebutuhan utama untuk menopang
kebutuhan hidup dalam memulai
kegiatan usaha yang akan mereka
lakukan. Minimnya modal usaha
menyebabkan mereka kesulitan
memulai usaha. Karena keterbatasan

modal yang tersedia mereka menilai pekerjaan serabutan seperti menjadi buruh, pedagang kecil keliling, dan membuka warung kecil merupakan pilihan rasional karena tidak perlu memerlukan modal yang banyak.

B. Faktor Struktural

Kemiskinan yang dialami oleh masyarakat Dusun Kentheng Kelurahan Semanggi di atas dikategorikan sebagai kemiskinan struktural yaitu kemiskinan yang disebabkan oleh faktor-faktor buatan manusia seperti kebijakan ekonomi yang tidak adil, distribusi aset produksi yang tidak merata, korupsi dan kolusi serta tatanan ekonomi dunia yang cenderung menguntungkan kelompok masyarakat tertentu. Hal ini oleh Kartasasmita (1996:236) disebut "accidental poverty", yaitu kemiskinan karena dampak dari suatu kebijaksanaan tertentu yang menyebabkan menurunnya tingkat kesejahteraan masyarakat. Pekerjaan masyarakat miskin yang tidak tetap seringkali menyebabkan mereka menganggur dan hanya menunggu panggilan kerja jika dibutuhkan. 
C. Sumber Daya Alam

Adanya alih fungsi lahan mempengaruhi kehidupan masyarakat di Dusun Kentheng. Tadinya kawasan tersebut memiliki lahan yang dapat ditanami dengan sayur-sayuran atau umbi-umbian. Namun karena kebutuhan masyarakat terkait tempat tinggal, lahan-lahan tersebut kemudian digunakan untuk membangun rumah. Peluang untuk mendapatkan penghasilan dari bercocok tanam saat ini telah

\begin{tabular}{ll}
\hline $\begin{array}{l}\text { Faktor } \\
\text { Penyeba } \\
\text { b }\end{array}$ & Akibat \\
\hline Fakt & - Minimnya \\
or & kepemilikan \\
Eko & modal usaha \\
nom & - Tidak mempunyai \\
i & banyak pilihan \\
& kerja $\quad$ \\
\hline Fakt & Kebijakan \\
or & yang tidak \\
Struk & merata \\
tural & Alih fungsi \\
\hline Faktor & lahan \\
Sumber & pertanian \\
Daya & menjadi \\
Alam & pemukiman \\
& Pendidikan \\
\hline Faktor & yang rendah \\
Sumber & Minimnya \\
Daya & keterampilan \\
Manusia & \\
& \\
\hline
\end{tabular}

hilang.
D. Sumber Daya Manusia

$$
\text { Sumber daya manusia }
$$
mempengaruhi kemiskinan di Dusun Kentheng, Semanggi. Pendidikan yang rendah, minimnya ketrampilan dan tanggungan keluarga yang relatif banyak menggambarkan rendahnya kualitas sumber daya manusia di dusun setempat. Rendahnya kualitas individu tersebut membuat masyarakat Dusun Kentheng tidak dapat mencapai standar yang ditentukan oleh lapangan-lapangan pekerjaan yang disediakan di kota.

\section{Tabel 1.3 Rekap Faktor Penyebab Kemiskinan Warga Dusun Kentheng Kelurahan Semanggi Kota Surakarta}

\section{Strategi dan upaya untuk bertahan}


dan keluar dari kemiskinan

Masyarakat Dusun Kentheng memiliki beberapa program yang dibuat untuk meningkatkan kesejahteraan masyarakat. Salah satu program yang dibuat adalah jimpitan. Cara kerjanya adalah, setiap kepala keluarga menyiapkan tempat kecil khusus untuk menaruh uang jimpitan, biasanya diletakkan di bagian kusen pintu. Setiap hari bisa memasukan uang dengan jumlah yang telah disepakati kedalam wadah kecil yang disediakan. Tiap minggunya, perangkat desa atau warga yang bertugas akan berkeliling untuk mengambil uang jimpitan yang terkumpul. Program jimpitan ini dilakukan secara rutin. Uang yang terkumpul dari hasil jimpitan digunakan untuk kepentingan bersama. Salah satu contoh penggunaan uang jimpitan adalah jika ada warga dusun yang sakit, uang ini digunakan untuk modal menjenguk. Uang tersebut juga digunakan sebagai modal untuk kegiatan-kegiatan kemasyarakatan yang ada di dusun tersebut. Selain itu di Dusun Kentheng juga memberlakukan iuran warga yang tentunya telah dimusyawarahkan terlebih dahulu sehingga tidak memberatkan warga. Seperti jimpitan, fungsi iuran ini juga untuk kepentingan bersama. Tabungan desa tentunya diperlukan untuk memfasilitasi dusun dengan sarana dan prasarana yang memadai.

\section{Relevansi Kemiskinan Dengan Solidaritas Sosial}

Solidaritas sosial merupakan perasaan atau ungkapan dalam sebuah kelompok yang dibentuk oleh kepentingan bersama. Durkheim membagi dua tipe solidaritas mekanis dan organis. Masyarakat yang ditandai oleh solidaritas mekanis menjadi satu dan padu karena seluruh orang adalah generalis. Ikatan dalam masyarakat ini terjadi karena mereka terlibat aktivitas dan juga tipe pekerjaan yang sama dan memiliki tanggung jawab yang sama. Sebaliknya, masyarakat yang ditandai oleh solidaritas organis bertahan bersama justru karena adanya perbedaan yang ada didalamnya, dengan fakta bahwa semua orang memilki pekerjaan dan tanggung jawab yang berbeda-beda (Ritzer dan Goodman, 2001).Masyarakat di Dusun Kentheng memiliki kebiasaan baik dalam hal saling tolong menolong. Mereka merupakan pendatang dengan latar belakang yang sama yaitu mencari pekerjaan di kota. Mereka berasal dari daerah yang berbeda-beda namun dapat hidup 
berdampingan. Salah satu faktor yang menyebabkan keteraturan semacam itu adalah adanya solidaritas antar masyarakat. Mereka merasa memiliki nasib yang sama sehingga menyadari pentingnya saling membantu.

\section{Gambar 1 dan 2. Potret Rumah Warga di Dusun Kentheng}

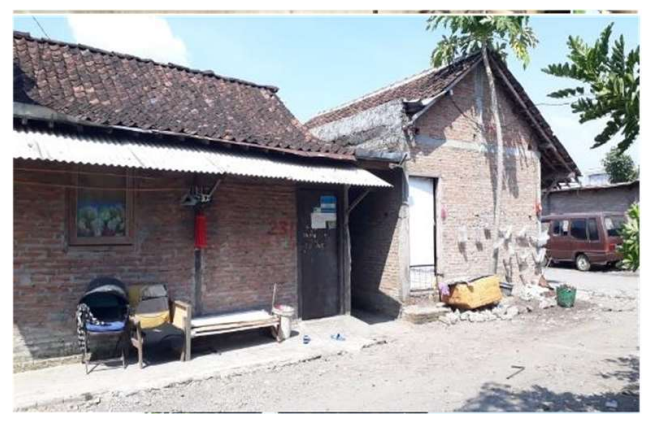

(Sumber: Dokumentasi Pribadi)

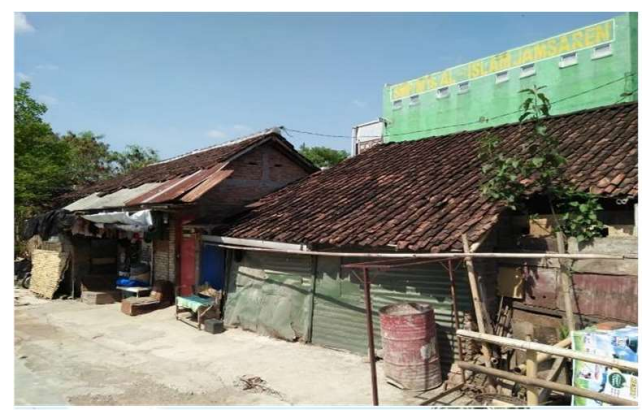

Menurut salah satu informan, orang-orang di dusun sangat menghargai satu sama lain. Ketika salah satu keluarga tertimpa musibah atau diberi ujian sakit, maka satu dusun akan membesuk keluarga ini dan memberikan bantuan seikhlasnya, atau biasanya juga dibantu dengan dana dari RT. Begitupun ketika salah satu keluarga tengah berbahagia misalnya selepas melahirkan, atau menikahkan anaknya, maka warga akan membantu keperluan-keperluan yang bersangkutan.

Sikap saling membantu tersebut muncul atas kesadaran bahwa kehidupan yang dilalui tidak bisa hanya diselesaikan sendirian, namun juga membutuhkan bantuan orang lain. Ketika masyarakat miskin merasa kekurangan, maka dengan saling tolong menolong, mereka akan merasa tercukupi. Selain bantuan dari sesama masyarakat, dusun marginal seperti Kentheng juga menerima bantuan dari pemerintah, sekitar 90\% masyarakatnya menerima tunjangan berupa bantuan langsung tunai maupun dalam bentuk dana infrastruktur untuk kepentingan masyarakat yang diberikan melalui RT.

\section{Pandangan Warga atas \\ Solidaritas Sosial}

Beberapa warga di Dusun Kentheng sendiri merupakan pendatang dari luar Kota Solo, dan memang profesi para pendatang turut menyesuaikan 
dengan masyarakat, seperti pedagang kecil, buruh, pekerja pabrik, maupun pekerja serabutan, bahkan ada yang berprofesi sebagai pengemis. Adanya pendatang dengan kesejahteraan yang kurang tersebut dianggap bukan suatu hal yang mengganggu jalannya interaksi yang terjadi antar warga.

\section{Grafik 1. Faktor Pembentuk}

\section{Solidaritas Sosial di Dusun Kentheng}

menurut beberapa warga merupakan salah satu yang memupuk kerekatan antara mereka, meskipun masih ada satu dua warga yang sama sekali tidak pernah bergabung dalam kegiatan bersama.

Apabila ada warga yang tidak pernah bergabung dalam perkumpulanperkumpulan di dusun, biasanya akan mendapatkan sanksi sosial. Individu yang menolak berinteraksi dengan yang lain tidak akan mendapatkan timbal balik dari

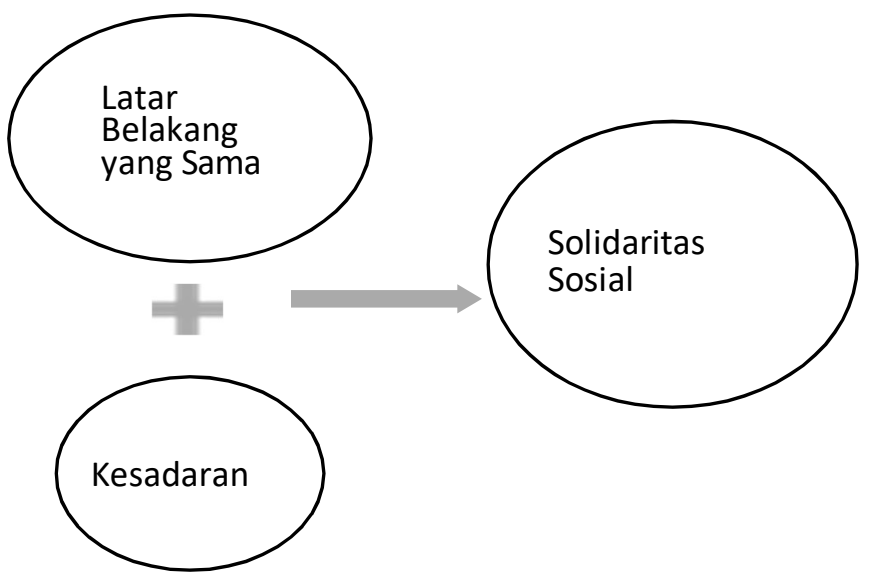

Informan Eko menyatakan bahwa perkumpulan-perkumpulan yang ada di Dusun Kentheng hingga saat ini masih berjalan dengan baik. Kelompokkelompok masyarakat seperti karang taruna, kelompok yasinan, dan PKK rutin melakukan pertemuan. Selain itu, setiap RT pada Dusun Kentheng juga memiliki jadwal pertemuan setiap bulan. Adanya kegiatan untuk kepentingan bersama ini masyarakat. Ketika pihak tersebut membutuhkan bantuan, masyarakat tidak dengan senang hati membantu. Masyarakat justru akan merasa acuh dan tidak peduli. Hal tersebut terjadi di Dusun Kentheng.

Menurut salah informan, hal tersebut tidak menjadi masalah, karena merupakan suatu hal yang wajar ketika dalam suatu wilayah yang masyarakatnya makin bertambah, tentu saja 
permasalahan yang ada juga semakin bertambah. Namun dengan syarat, masyarakat setempat baik warga asli maupun pendatang mampu berinteraksi satu sama lain. Dengan demikian masyarakat akan saling membantu, dan kerukunan antar warga kembali terjalin.

\section{Pengalaman Konflik antar Masyarakat}

Berdasarkan penuturan informan, di Dusun Kentheng jarang sekali terjadi konflik antar masyarakat. Satu dua kali dialami oleh beberapa orang saja, kurang lebih dengan alasan ketidakcocokan antara masyarakat dan perangkat desa. Namun setelah diadakan pertemuan yang melibatkan warga yang lain, akhirnya masalah tersebut dapat diselesaikan juga. Mengingat tiap warga merasa tetap membutuhkan satu sama lain, sehingga menimbulkan kesadaran masing-masing untuk tidak mudah terjerumus dalam suatu masalah, karena khawatir tidak akan mendapat perlakuan baik dari warga masyarakat yang lain.

Dusun Kentheng merupakan sebuah kawasan dengan masyarakat berpendidikan rendah. Sebagian besar masyarakatnya paling tinggi hanya lulusan SMA. Mereka mencoba menyekolahkan anak-anak mereka agar lebih berkembang dan maju dibanding orang tuanya, namun masih ada beberapa anak yang pada akhirnya putus sekolah dan bekerja serabutan seperti orang tuanya.

Masyarakat di kawasan ini cenderung bekerja untuk sekedar memenuhi kebutuhan sehari-hari, masih minim keluarga yang benarbenar menabung untuk kehidupan yang akan datang. Kebudayaan seperti inilah yang kemudian disebut sebagai budaya kemiskinan yang seringkali terjadi di kota. Dengan begitu, masyarakat miskin ini hanya memiliki modal solidaritas antar warga yang melindungi kehidupan mereka. Adanya perasaan yang sama terhadap nasib dan pola hidup membuat masyarakat merasa aman karena tidak ada kesenjangan.

Masyarakat saling membantu satu sama lain dan bergotong royong untuk kepentingan bersama. Keyakinan akan selalu terpenuhinya kebutuhan dari hubungan timbal balik antar warga ini pada dasarnya menimbulkan perilaku yang stagnan dalam 
masyarakat, sehingga pola hidup yang kurang baik menjadi kebiasaan. Kondisi tersebut membuat mereka hidup dalam lingkaran kemiskinan. Masyarakat ini kemudian tidak memiliki dorongan untuk mencapai kesejahteraan yang sebenarnya. Bagi masyarakat ini, selama hari ini mereka masih memiliki tetangga untuk dimintai bantuan, maka kehidupan mereka masih baik-baik saja, dan akan berjalan sebagaimana mestinya secara berdampingan.

\section{Simpulan}

Kemiskinan saat ini bukan lagi menggandeng aspek ekonomi saja dan bukan lagi mengenai sulitnya pemenuhan kebutuhan pokok masyarakat. Namun ukuran kemiskinan yang terjadi di kota adalah tentang masyarakat yang tidak mau berkembang dalam menjalani pola hidup. Kemiskinan yang terjadi disebabkan karena adanya warisan budaya perilaku generasi sebelumnya bahwa mendapatkan penghasilan yang cukup untuk hidup hari ini merupakan suatu hal yang cukup. Tidak perlu lagi mencari tambahan pendapatan, tidak perlu bersusah payah menabung terlalu banyak untuk keperluan dimasa yang akan datang. Dalam kaitannya dengan solidaritas sosial dalam masyarakat di Dusun Kentheng, orangorang dengan pola hidup seperti yang telah disebutkan merasa bahwa meskipun mereka tidak mampu memenuhi kebutuhan, maka masih ada orang-orang disekitarnya yang akan membantu. Dengan latar belakang kemiskinan yang sama antar masyarakat menimbulkan rasa saling memahami. Namun masyarakat Dusun Kentheng terpantau rukun dan memiliki solidaritas yang tinggi, saling menghargai satu sama lain, tolong menolong, dan bekerja sama untuk memenuhi kebutuhan bersama. Dapat disimpulkan bahwa persamaan nasib dalam lingkungan masyarakat mampu memunculkan solidaritas antar masyarakat sehingga masing-masing individu merasa saling membutuhkan.

\section{Ucapan Terima Kasih}

Terima kasih disampaikan kepada semua pihak yang terlibat dalam penulisan artikel ini, sehingga terlaksana dengan baik, serta kepada tim redaksi Jurnal Dimensia Prodi 
Pendidikan Sosiologi Fakultas IImu

Sosial UNY yang telah

mempublikasikan karya ini.

\section{Daftar Pustaka}

Abdullah, Taufik \& A. C. Van Der Leeden, (1986), Durkheim dan Pengantar Sosiologi Moralitas. Jakarta: Yayasan Obor Indonesia.

Aswadi., Haris, Murtafik Ahmad. (2012). Solidaritas Masyarakat Pinggiran. Jurnal Sosiologi Islam. Vol 2 (2): 67 $-86$.

Ishak, Mahmud. (2013). Kemiskinan dan Pengaruhnya Terhadap Kejahatan dalam Perspektif Sosiologis dan Teologis. Jurnal Fakultas Syariah dan Ekonomi Islam IAIN Ambon. Vol 9(1): $122-136$

Kumurur, A $\quad$ Aeronica.(2009). Pembangunan dan Kemiskinan Perempuan di Kota. Ekoton. Vol. 9 (1): $73-86$.

Lewis, Oscar, (1993), Kebudayaan Kemiskinan, dikutip dari Parsudi Suparlan, Kemiskinan di Perkotaan. Jakarta: Yayasan Obor.

Suhartono, Dicky., Kanto, Sanggar., Mu'adi, Sholih. (2014). Kajian Tentang Makna, Penyebab dan
Strategi

Penang gulangan Kemiskinan. Wacana. Vol 17(4) $234-245$.

Yunus, M \& K. Weber. (2008).

Menciptakan Dunia Tanpa Kemiskinan. Terj. dari Creating World Without Poverty oleh Rani.

R. Moediarta. PT. Gramedia Pustaka Utama. Jakarta (261 hlm).

Klasen, S. (2009). Inequality in emerging countries: Trends, interpretations, and implications for development and poverty reduction. Intereconomics, 44(6), 360.

Wratten, E. (1995). Conceptualizing urban poverty. Environment and urbanization, 7(1), 11-38.

Badan Pusat Statistik. (2018). Statistik Indonesia (Statistical Yearbook of Indonesia 2018). BPS-Statistics Indonesia

Jellinek, L. (1992). Indonesia: Strategy for a Sustained Reduction in Poverty.

Suparlan, P. (1984). Gelandangan: Sebuah konsekuensi perkembangan kota, dalam gelandangan pandangan ilmu sosial. Jakarta: LP3ES.

Blank, R. M., Card, D., Levy, F., \& Medoff, 
J. L. (1993). Poverty, income distribution, and growth: Are they still connected?. Brookings Papers on Economic Activity, 1993(2), 285339.

Suryawati, C. (2005). Memahami kemiskinan secara multidimensional. Jurnal Manajemen Pelayanan Kesehatan, 8(03).

Lin, Kuan-Hui, and Chang-Yi Chang. "Everyday crises: marginal society livelihood vulnerability and adaptability to hazards." Progress in Development Studies 13.1 (2013): 1-18.

Kartasasmita, G. (1996). Pembangunan untuk rakyat: memadukan pertumbuhan dan pemerataan. Cides.

Ritzer, G., \& Goodman, D. (2001).
Postmodern social theory. In Handbook of sociological theory (pp. 151-169). Springer, Boston, MA. 